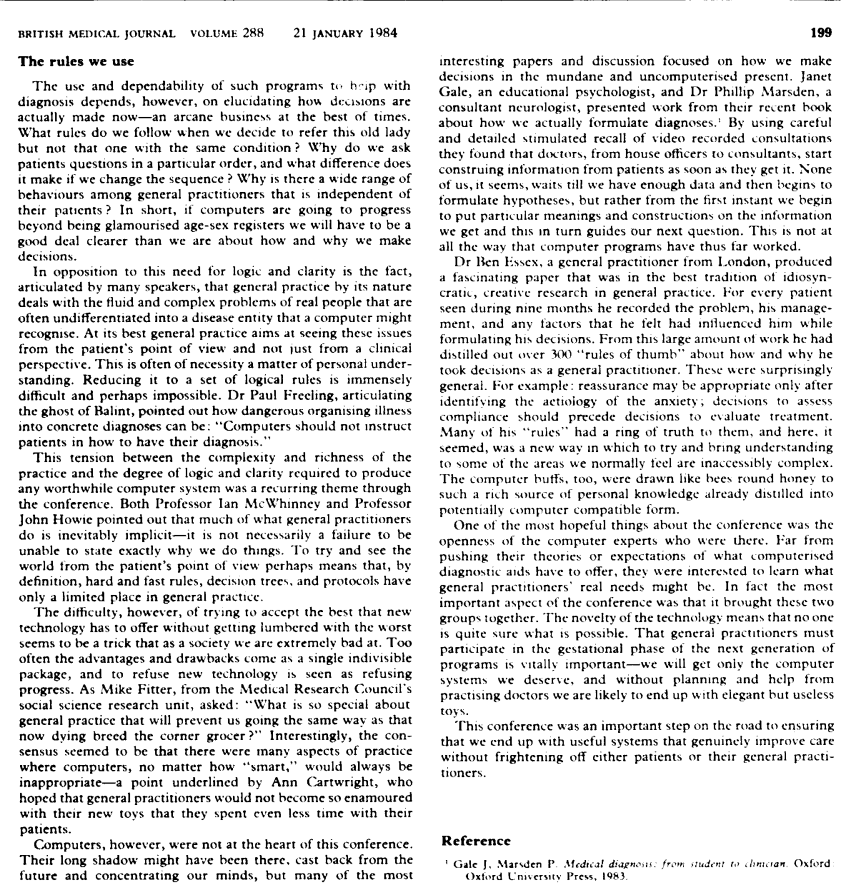

ONE HUNDRED YEARS AGO Hinton's plaster-of-Paris

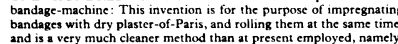

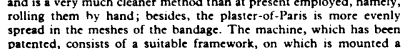

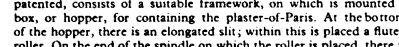

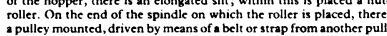

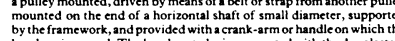
by the framework, and provided with hacrank-arm or handle on which the
bandage is wound. The bandage to be impregrasted with the dry plaster-
of -Paris is passed under the machinc, and brought round the roller at

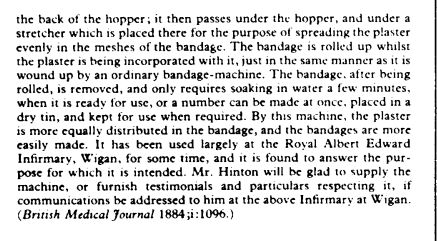

200

BRITISH MEDICAL JOURNAL VOLUME $288 \quad 21$ JANUARY 1984

\section{Practice Research}

\section{Well man clinic in general practice}

G N MARSH, C CHEW

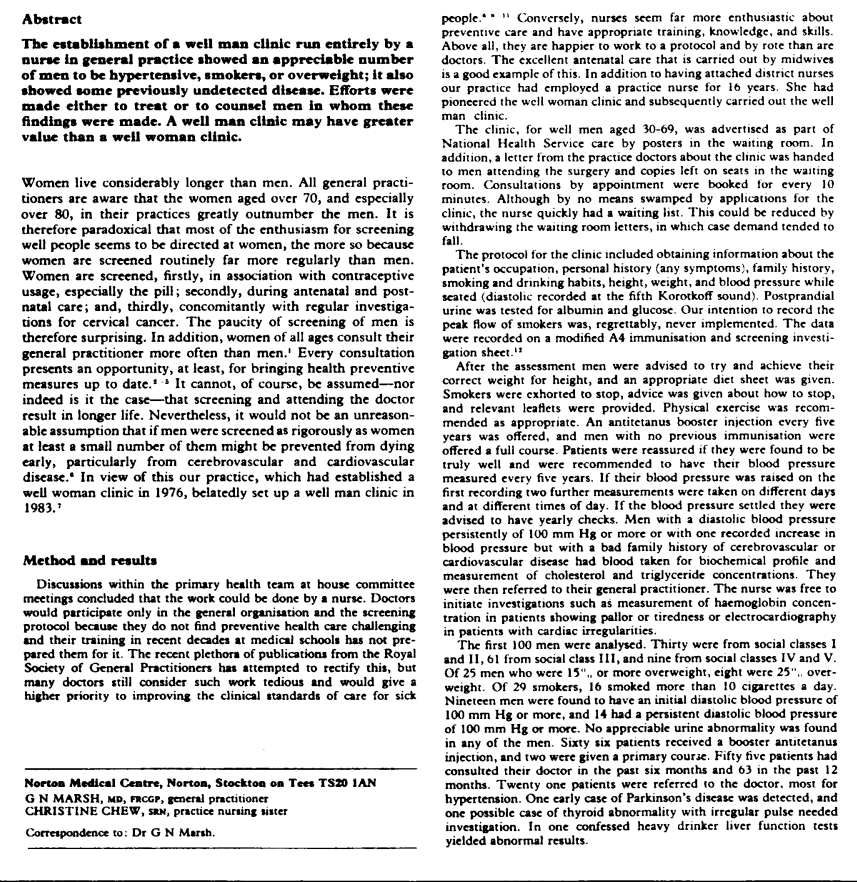

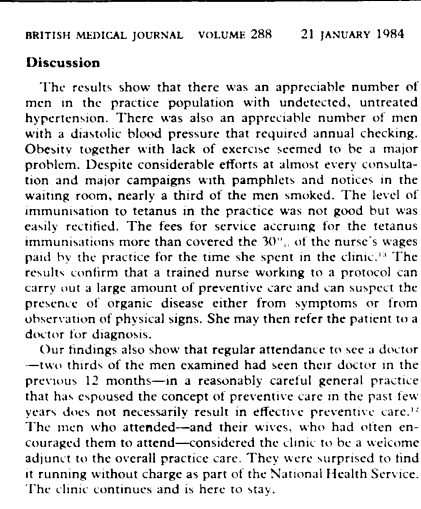

201

References

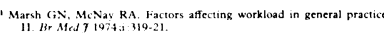

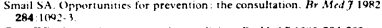

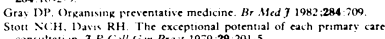

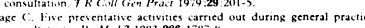

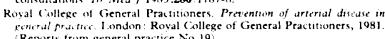

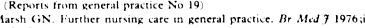

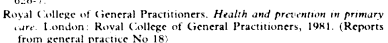

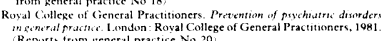

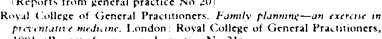

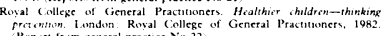

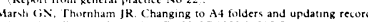

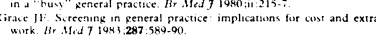

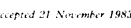

\title{
Medical rehousing
}

E L HOWELLS

Abstract

A local authority and its medical adviser collaborated to
assess the needs of ments for medical rehousings. Shome characteristsics of the
applicants were examined, together with how successfully applicants were examined, logether with how successfull
their needs were met. Over half the applicants were aped
over 55 . Some three years after their initial applicatio over 55 . Some three years after their initial application
$41 \%$ of applicants considered to have medical priority
had been rehoused compared with $36 \%$ of those with no
medical priority.

Introduction

The adverse effects of substandard housing on health have long

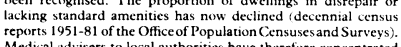
on giving advice on how to metet the needs of thosc who for
medical reasons have special requirements for rehousing. medical reasons have special requirements fur rchousing.
report here a study of applications for rehousing in Portsmouth,

Community Medicine Department, Civic Offices, Portsmouth PO E. L. HOWTELLS, MFCM, scrior clinical medical office

which has a population of 175000 , of whom 104000 live in
owner occupied dwellings, 25000 in privately rented accommodation, and 41 clo in council owned dwellings.' In addition, the
city owns dwellings housing 60000 people in a neighbouring Procedures and policies

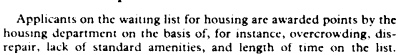

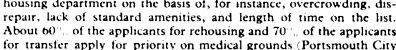

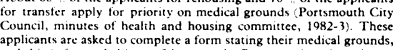

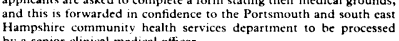

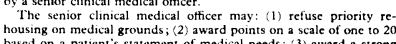

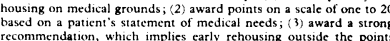

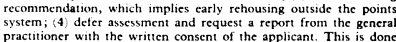

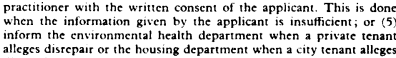
distrepair. points awarded are added to the applicant's points total. The
criteria for awarding priority on medical grounds were arrived at $b$
b

202

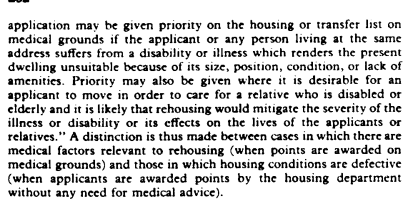

Methods of study and results

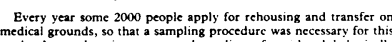

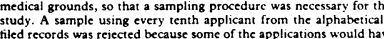

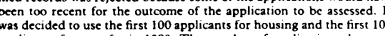

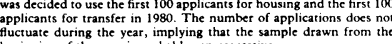

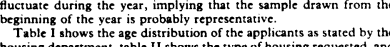

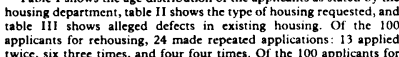
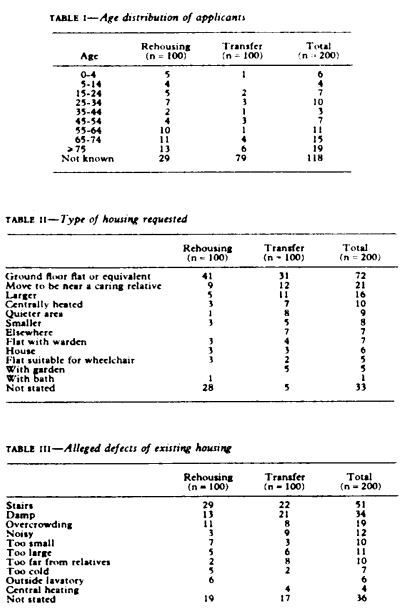

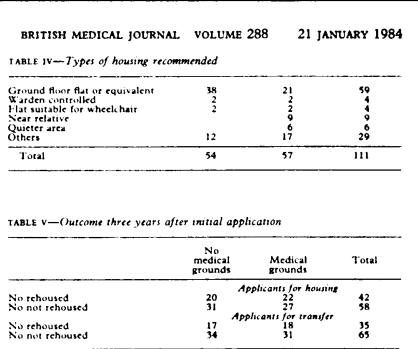

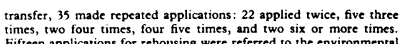

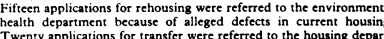

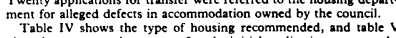

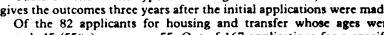

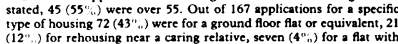

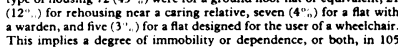

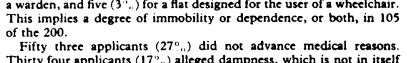

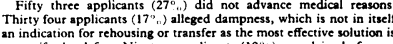

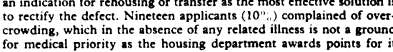

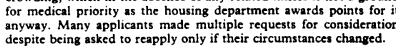
Discussion At first sight the system of awarding points for medical
priority appears to have litte effect on the chance of an applicant
being rehoused or transferred. The award of points, however, being rechoused or transferede. The award of points, however,
increases the applicant's points total and thus, to acerain
extent, must accelerate rehousing or transfer. Applicants with special housing requirements are possibly more difficult to place
than those without. Our experience with the success of rehousing people contrasts with hat of Gray, who found that fewer than

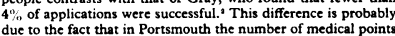

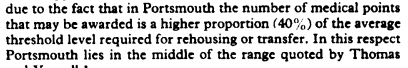

References
I Officc of Population Censuses and Surveys. Cenmus I98I. London: HMSO,

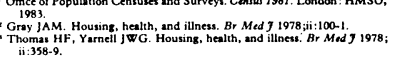
(Ascepped 24 October 1983) 